\title{
Vaccine-specific T-cell proliferation in response to a dual peptide cancer vaccine in breast and ovarian cancer patients
}

\author{
Erika J Schneble ${ }^{1 *}$, John S Berry ${ }^{1}$, Alfred F Trappey ${ }^{1}$, Timothy J Vreeland ${ }^{1}$, Diane F Hale ${ }^{1}$, Alan K Sears ${ }^{1}$, \\ Guy $T$ Clifton ${ }^{4}$, Sathibalan Ponniahn', Nathan M Shumway ${ }^{3}$, Elizabeth A Mittendorf ${ }^{2}$, George E Peoples ${ }^{1}$ \\ From Society for Immunotherapy of Cancer 28th Annual Meeting \\ National Harbor, MD, USA. 8-10 November 2013
}

\section{Background}

HER2 is a commonly expressed tumor-associated antigen in breast $(\mathrm{BrCa})$ and, therefore, an attractive target for immunotherapy. We have investigated HER2-derived peptides as vaccines mixed with GM-CSF to include GP2 (a HLA-A2 and HLA-A3 restricted, CD8+ eliciting epitope) and AE37 (a HLA unrestricted, MHC class II, CD4 + eliciting epitope). Both peptide vaccines (PV) have shown clinical promise individually and there is clear rationale for combining GP2 and AE37 to elicit a more robust immune response (IR) of both CD4+ and CD8+ $\mathrm{T}$ cells. Here, we report the results of in vitro, CD8+, $\mathrm{T}$-cell proliferation in response to the AE37 epitope.

\section{Methods}

After completion of standard therapy, disease-free, node positive or high-risk, node negative $\mathrm{BrCa}$ or ovarian cancer patients received AE37/GP2+GM-CSF in six monthly intradermal inoculations (R1-R6). To determine HER2induced proliferation, a $3 \mathrm{H}$-thymidine incorporation assay was used. Specifically, peripheral mononuclear blood cells (PMBC) were isolated from blood samples taken at baseline, R3, R6, six months after the primary vaccine series (RC6), and 12 months post-PVS (RC12). PMBC were then exposed to the AE37 peptide or culture media (CM) as a control. After incubation with radioactive-thymidine and cell lysis, a scintillation counter was used to measure the amount of thymidine incorporation into DNA in counts per minute (cpm). Data are expressed as means +/-SEM and compared using student's t-test.

${ }^{1}$ San Antonio Military Medical Center, San Antonio, TX, USA

Full list of author information is available at the end of the article
Table 1

\begin{tabular}{cccccc}
\hline & R0 & R3 & R6 & RC6 & RC12 \\
\hline AE37 & 1023.9 & 2457.4 & 2170.3 & 3494.1 & 2891.8 \\
& +216.7 & +685.4 & +461.6 & +1442.5 & +1542.8 \\
CM & 1405.9 & 1119.7 & 2027.2 & 1612.9 & 1370.1 \\
& +260.6 & +307.9 & +682.8 & +331.4 & +367.8 \\
p-value & 0.57 & 0.02 & 0.06 & 0.11 & 0.35 \\
\hline
\end{tabular}

\section{Results}

Of the 28 vaccinated patients, $\mathrm{PMBC}$ from 22 patients were available. Data units are measured in cpm. Results are presented in the table below (Table 1).

\section{Conclusions}

During the primary vaccination series, an AE37/GP2+GMCSF dual peptide vaccine results in robust $\mathrm{T}$-cell proliferation. However, significant immune responses become more variable at six and twelve months post vaccination suggesting the need for boosters in some individuals.

\section{Authors' details}

${ }^{1}$ San Antonio Military Medical Center, San Antonio, TX, USA. ${ }^{2}$ MD Anderson Cancer Center, Houston, TX, USA. ${ }^{3}$ Uniformed Services University of Health Sciences, Bethesda, MD, USA. ${ }^{4}$ Blanchfield Army Community Hospital, Fort Campbell, KY, USA.

Published: 7 November 2013

doi:10.1186/2051-1426-1-S1-P236

Cite this article as: Schneble et al:: Vaccine-specific T-cell proliferation in response to a dual peptide cancer vaccine in breast and ovarian cancer patients. Journal for ImmunoTherapy of Cancer 2013 1(Suppl 1):P236. 